\title{
Aircraft accident investigation: the decision-making in initial action scenario
}

\author{
Marcia M. Barreto ${ }^{\mathrm{a},{ }^{*}}$, Selma L. O. Ribeiro ${ }^{\mathrm{b}, \mathrm{c}}$ \\ ${ }^{\mathrm{a} b}$ Aeronautical Engineering Division (IEA.) Technological Institute of Aeronautics (ITA). Professional Master \\ Course in Aviation Safety and Continued Airworthiness. \\ ${ }^{\mathrm{b}}$ National Institute for the Spatial and Aeronautical Development - IDEA, Av. Franklin Roosevelt, 194, gr. 507, \\ Centro Rio de Janeiro-RJ, Brazil, ZC.20.021-120 \\ ${ }^{\mathrm{c}}$ Estácio de Sá University
}

\begin{abstract}
In the complex aeronautical environment, the efforts in terms of operational safety involve the adoption of proactive and reactive measures. The process of investigation begins right after the occurrence of the aeronautical accident, through the initial action. Thus, it is in the crisis scenario, that the person responsible for the initial action makes decisions and gathers the necessary information for the subsequent phases of the investigation process. Within this scenario, which is a natural environment, researches have shown the fragility of rational models of decision making. The theoretical perspective of naturalistic decision making constitutes a breakthrough in the understanding of decision problems demanded by real world. The proposal of this study was to verify if the initial action, after the occurrence of an accident, and the decision-making strategies, used by the investigators responsible for this activity, are characteristic of the naturalistic decision making theoretical approach. To attend the proposed objective a descriptive research was undertaken with a sample of professionals that work in this activity. The data collected through individual interviews were analyzed and the results demonstrated that the initial action environment, which includes restricted time, dynamic conditions, the presence of multiple actors, stress and insufficient information is characteristic of the naturalistic decision making. They also demonstrated that, when the investigators make their decisions, they use their experience and the mental simulation, intuition, improvisation, metaphors and analogues cases, as strategies, all of them related to the naturalistic approach of decision making, in order to satisfy the needs of the situation and reach the objectives of the initial action in the accident scenario.
\end{abstract}

Keywords: Accident investigation, decision making, natural environment, naturalistic decision making, initial action.

\section{Introduction}

In the complex aeronautical environment, the efforts in terms of operational security involve the adoption of proactive measures, since the aircraft project design until its operation, and reactive measures, resulting from the investigation of aeronautical incidents and accidents.

In Brazil, the investigation of aeronautical incidents, aiming at its prevention, is carried out by the Aeronautical Accident Investigation and Prevention Center - Centro de Investigação e Prevenção de Acidentes Aeronáuticos (CENIPA).
The use of investigation as a prevention tool includes a broad analysis that goes beyond the immediate cause and is focused in the performance of the final operator that considers the current management and organizational conditions in the accident origin.

Thus, the investigation starts at the accident location and continues to the pre-accident period of time, in order to detail the complexes interactions that occurred in the working environment which resulted in the accident.

This gives the people responsible for the aeronautical accident investigation very different working conditions. The collection of information about the pre-accident is the target of a detailed

\footnotetext{
*Corresponding author. E-mail: mmolinarister@gmail.com.
} 
planning, and various sources are used which include data from the initial action, flight reports, interviews, documentation and bibliographical research, and takes place in a scenario far away from the accident location. On the other hand, the first information, necessary for the subsequent phases of the investigation process, shall be obtained at the accident location. This location is constituted by a scene of absolute crisis, especially in catastrophic events, where the victims' pain and suffering are confused with the work of the firemen, the police, civil defense, medical doctors, journalists and investigators, and where time is often a determinant factor for data collection.

Generally, this initial activity, so-called initial action, includes actions such as: wreckage sketch and the aircraft flight profile, collection of preliminary information provided by the witnesses and collection of relevant data to understand the accident, which shall be listed, identified, registered and photographed.

Considering the context characteristics and the tasks that compose the initial action and its importance for the investigation process, some observations are relevant.

The complexity that involves the accident occurrence implies understanding it simultaneously as a representative phenomenon of common situations and, at the same time, being a unique case, since the factors that determined the rupture of the working process were aligned one time only [1].

This dimension of the accident singularity implies the need for the one responsible for the initial action to seek for relevant information for the process and make decisions, for example, concerning the wreckage protection, in an uncertain and new scenario.

In the extremely dynamic accident scenario, the time factor becomes particularly important. The one responsible for the initial action needs to take immediate measures in order to preserve the signs, considering that many relevant information could be lost or be object of change due to the diversity of actions that are carried out in the accident location by the other teams or by the behavior of curious people.

The appropriate management of time involves the setting of priorities, in performing tasks and the optimization of available resources, through the adequate coordination with the other professionals present at the accident scene.

We note that the initial action occurs in a natural environment, under changeable conditions, imprecise information and time limitation, and, in this context, researches have proven the fragility of decision making rational models, that are focused in the welldefined objectives, creation and evaluation of alternatives and choices. [2].

\section{Objective}

The starting point that guided this study was to verify whether the initial action, after the aeronautical accident occurrence, and the decision making strategies, used by the investigators, responsible for conducting this activity, are characteristic of Klein's proposal [2] about the naturalistic decision making.

\section{Naturalistic decision making, according to Klein}

The naturalistic decision making can be defined as "[...] the way people use their experience to make decisions in field environments" [3].

The researches focus are the real world situations and, the factors that characterize the naturalistic decision making environment are [2]: little structured problems; dynamic and uncertain environment where the situation develops quickly; insufficient information (missing, ambiguous or wrong); multiple actors, with different views of the situation; presence of multiple objectives that may be not well defined; high risk environment and time pressure.

Besides the environment characteristics, the decision maker characteristics, beginner or an experienced one, is an aspect emphasized in the researches done about decision making in natural scenarios. The challenge is to identify how people use their experience to decide quickly and effectively in real situations.

According to Klein [2], experience is the base for - the broad set of capabilities that people use to make their decisions in high risk natural environment and under time pressure. In his researches he focused on the human capabilities strengths, denominated power sources, which contribute to understand how people think and decide in these environments, including: intuition, mental simulations narrative, metaphors and analogue cases.

"Intuition depends on the use of experience to identify key patterns that indicate the situation dynamics" [2]. When evaluating a situation, the experts use their experience to recognize whether it is a typical case or if there are ruptures in the expected pattern or frustrated expectations. 
The mental simulation refers to the ability of imagining events that took place in the past or that will take place in the future [2]. It is the process that allow us to explain how the events developed from the past to the present and project how the present will develop into the future [2].

The narratives organize the events in a significant structure, contributing to its understanding. It is a construction that describes important causes for the occurrence of an event.

The use of metaphors and analogue cases, when allowing the understanding of a new situation from another situation previously experienced, contributes to reduce the uncertainty notice in the environment and to provide an indication on how to proceed.

\section{Methodological procedures}

Aiming at identifying the scenario characteristics of the initial action and the strategies used by the investigators in this environment, a descriptive research was conducted with a non-probabilistic sample, by accessibility, composed by seven professionals that have been working in this field for more than two years.

For the data collection, individual interviews were conducted, using a script based on the critical decision method, developed by Klein [2].

After the interviews' transcriptions, the information was treated using the content analysis technique [4]. In reference to extracts of the answers given by the investigators to the themes covered, 136 registry units were extracted, grouped in 31 categories (Table 1).

Table 1

Themes covered in the interviews and categories of the answers obtained.

\begin{tabular}{|c|c|c|c|}
\hline Themes & Registry Units & Categories & $\mathrm{F}$ \\
\hline Startup activities & 09 & $\begin{array}{l}\text { Unpredictability } \\
\text { Lack of information }\end{array}$ & $\begin{array}{l}08 \\
01\end{array}$ \\
\hline Training for the initial action & 19 & $\begin{array}{l}\text { Procedures for data collection } \\
\text { Management of the situation } \\
\text { Practical examples }\end{array}$ & $\begin{array}{l}16 \\
02 \\
01\end{array}$ \\
\hline First impressions of the scenario & 27 & $\begin{array}{l}\text { Dynamic environment } \\
\text { Multiple actors } \\
\text { Chaotic environment } \\
\text { Stress }\end{array}$ & $\begin{array}{l}11 \\
09 \\
06 \\
01\end{array}$ \\
\hline Focus of the performance on the intial action & 37 & $\begin{array}{l}\text { Data preservation } \\
\text { Time } \\
\text { Knowledge of the area } \\
\text { Integration with other actors } \\
\text { Emotional control }\end{array}$ & $\begin{array}{l}11 \\
09 \\
09 \\
07 \\
01\end{array}$ \\
\hline Influence of the previous experience & 18 & $\begin{array}{l}\text { Data collection } \\
\text { Out of the pattern situation } \\
\text { Emotional control } \\
\text { Avoid pre conceived ideas } \\
\text { Other controls } \\
\text { Intuition } \\
\text { Report making }\end{array}$ & $\begin{array}{l}03 \\
03 \\
03 \\
03 \\
03 \\
02 \\
01\end{array}$ \\
\hline Pattern scenario and accident & 04 & New scenario & 04 \\
\hline Knowledge sources used in the initial action & 06 & $\begin{array}{l}\text { Reformulation of the initial } \\
\text { hypothesis } \\
\text { Mental simulation } \\
\text { Improvisation }\end{array}$ & $\begin{array}{l}03 \\
02 \\
01\end{array}$ \\
\hline Strategies used after start up & 04 & Search for previous information & 04 \\
\hline Expectations when arriving at the accident scenario & 06 & $\begin{array}{l}\text { Data collection } \\
\text { Apply procedures } \\
\text { Emotions control }\end{array}$ & $\begin{array}{l}03 \\
02 \\
01\end{array}$ \\
\hline Possible mistakes when carrying out the initial action & 06 & $\begin{array}{l}\text { Hurry } \\
\text { Improper registry }\end{array}$ & $\begin{array}{l}04 \\
02\end{array}$ \\
\hline Total & 136 & - & 136 \\
\hline
\end{tabular}




\section{Results}

The answers obtained in the theme "Startup characteristics", "Pattern scenario and accident" and "First impressions on the scenario", allowed characterizing the context in which the initial action is carried out.

The startup to participate in an initial action is characterized by the unpredictability and the professional, when called, has little information about the aircraft, number and situation of the victims, cargo being transported and characteristics of the region.

In the answers included under the theme "Strategies used after startup", it was noted that, during the displacement to the scenario, the investigator establishes contacts with the search and rescue team with the objective of collecting data that allow the planning of their activities at the location.

In the answers sent in the theme "Pattern scenario and accident" it was proven that the investigators perceive the accident as a new and unique and new event.

The data obtained together with the interviewees and contained in the theme "First impressions on the scenario" point out to a scenario with the following characteristics: dynamic environment, with the presence of multiple professionals, chaotic and with high stress load.

The strategies used by the investigators when carrying out the initial action were proven in the answers included in the themes: "Focus of the performance in the initial action", "Sources of knowledge used in the initial action" and "Training for the initial action".

According to the data collected in the interviews, the focus of the performance of the investigators in the initial action is the preservation of the data to be collected. For this, they need to prioritize activities and manage adequately the time available, in order to avoid that some signs are lost. Besides, they pointed the integration with the other teams that work in the scenario and the contact with witnesses as contributing factors to the collection of initial information about the accident.

It was reported in the answers to the theme "Training for the initial action", that were trained in the procedures for the data collection about the wreckage such as, for example, analysis of the efforts to which the parts of the aircraft and fire marks were submitted. For the management of the various demands derived from the accident situation, as for example, integration with other teams and contact with the families, informed that they use the knowledge obtained in trainings carried out in other areas.

The answers obtained in the theme "Sources of knowledge used in the initial action" showed the use of mental simulation, when imagining how the events developed until the accident, and the improvisation of procedures, in order to entering the aircraft which is situated in a place of difficult access.

Regarding the answers obtained in the theme "Influence of the previous experience", the reports point to various contributions that assist the investigator in reaching the objective established for the activity, being: collect data on the accident.

According to the interviewees, the experience, aside from allowing the adequate control of emotions mobilized by the accident scenario, contributes to: keep the attention focused in the relevant information for the initial action, to make a quick evaluation of the situation through intuition and to detect aspects of the situation that escape from the expected pattern.

The themes "Expectations when arriving at the accident scenario" and "Possible mistakes when carrying out the initial action" were not subject of analysis in this paper.

\section{Final considerations}

The research carried out allowed the identification of some characteristics of the context, in which the initial action is carried out as well as, to obtain an understanding of the strategies that the investigators use to decide in this environment.

According to the results, the aspects that characterize the context in which the initial action is carried out: unpredictability, lack of information, dynamic environment with the presence of multiple professional, chaotic and with high load of stress are compatible to the naturalistic decision making environment, according to Orasanu and Connolly [5].

It can also be verified that, when making their decisions in the initial action scenario, the professional use their experience and the strategies of mental simulation, intuition and improvisation, related to the model of naturalistic decision making and considered by Klein [2] such as power sources, in order to satisfy the situation needs and reach their objectives in the accident scenario.

Thus, the incorporation of the knowledge originated from the researches on naturalistic decision making, to prepare the ones responsible for 
conducting the initial action, would be an important resource to improve the decision process in the context of this activity. Another strategy would be the creation of conditions so that the people responsible for the initial action could acquire experience faster, considering that experience plays a fundamental role for well succeeded decisions in natural environments.

\section{References}

[1] C.M. Freitas, M.F Souza and J.M.H Machado (Org.) Acidentes industriais ampliados: desafios e perspectivas para o controle e prevenção, Editora FIOCRUZ, Rio de Janeiro, 2000.

[2] G. Klein, Fontes do poder: o modo como as pessoas tomam decisões. Instituto Piaget, Lisboa, 1998.

[3] J.S. Pruitt, J.A. Cannon-Bowers and E. Salas, In search of naturalistic decisions, in: R. Flin, et al. Decision making under stress: emerging themes and applications, Ashgate Publishing Limited, Aldershot, 1997. pp. 30-40.

[4] L. Bardin, Análise de conteúdo. Edições 70, Lisboa, 1977.

[5] J. Orasanu and T. Connolly, The reinvention of decision making, in: G. Klein, J. Orasanu, R. Calderwood and C.E. Zsambok (Eds.), Decision making in action: models and methods. Ablex Publishing Co., Norwood, NJ, 1993 